\title{
Diagnostic features of three nymphal instars of Sturnidoecus bannoo (Phthiraptera: Ischnocera) infesting Bank Myna Acridotheres ginginianus
}

\author{
Sweta Rajput*, V.D. Joshi*, Nayanci Bansal, Aftab Ahmad and A.K.Saxena** \\ Department of Zoology, Government Raza Postgraduate College, Rampur-244901 (U.P.), INDIA \\ *Department of Zoology, Government P. G. College, Kotdwara (Uttrananchal), INDIA \\ **Corresponding author. E-mail: akscsir@ rediffmail.com
}

Abstract: Three nymphal instars of bank Myna louse, Sturnidoecus bannoo differ from each other not only any size, abdominal segmentation, chitinization but also in the number of setae occurring on head, thorax and abdomen. Present report provides information on the diagnostic characters of three nymphal instars of the aforesaid louse.

Keywords: Bank Myna louse, Lschnocera, Phthiraptera

\section{INTRODUCTION}

Morphological features of adults are generally used in systemic studies on avian lice. Since, the three nymphal instars of any louse species appear so similar (excepting the size), their identification is a challenging task.

While describing the in vitro bionomics of selected avian lice, certain workers have given an account of morphology of their nymphal instars. Specific studies on the nymphal morphology of selected species have been made by Clay (1958) and Modrejewska and Zlotorzycka (1987). Based on the external morphology of nymphal instars, Mey (1994) made first comprehensive attempt to deduce the phylogeny of ischnoceran bird lice. Price and Hellenthal (1996) have highlighted the importance of nymphal morphology to elucidate the louse relationship. Workers like Lonc and Modrejewska (1986, 89), Page et al. (1995), Saxena et al (1998), Smith (2000), Cicchino and Castro (2002) and Silke (2006) have also made contribution in this field.

During the present investigations an attempt has been made to describe the diagnostic characters of the three nymphal instars of an ischnoceran louse, Sturnidoecus bannoo parasitizing, Indian bank Myna Acridotheres ginginianus.

\section{MATERIALS AND METHODS}

Nymphal instars of Sturnidoecus bannoo, obtained by culturing the lice in vitro condition (by the method suggested by Gupta et al., 2007), were treated with $20 \%$ $\mathrm{KOH}$ (24 hrs), washed thrice (in water), passed through $10 \%$ Acetic acid (40 minute), stained (aqueous acid fuchsin), dehydrated (ethanol series), cleared (clove oil), mounted (Canada balsam) and subjected to microscopy, to record the morphology and chaetotaxy. The chaetotaxy of three nymphal instar presented in Table 1.

\section{RESULTS}

First instar nymph: The description of the first instar nymph (Fig. 1) is based on the characters of 4-5 days old specimens reared in the laboratory. The nymph measures $0.7 \mathrm{~mm}$ in length and $0.3 \mathrm{~mm}$ in width. Head is little longer than broad. Hyaline margin of the first instar is notched. Anterior plate poorly seen. Premarginal carina and occipital carina are thin and not delined clearly. Rounded pre-antetennal nodi are medium sized. Coni are undeveloped. Cutting edges of mandible are not visible. Ventral carina weekly sclerotized. Pulvinus clear. Antennae five segmented. Post antennal nodus is absent. Pair of eyes not seen at this stage. Temple margin angular. Temporal carina absent. Gular plate and lingual sclerite poorly developed. Tentorial bridge not seen.

Marginal temporal seta (M.T.S.) 4 and 5 present on each half. One ocular seta, one anterior dorsal seta, one IInd Anterior seta, one dorsal submarginal seta, one Ist ventral submarginal seta, one IInd ventral submarginal seta present on each half.

Prothorax is rectangular, bare; its anterior margin lies under the occipital margin of the head. Meso- and metathorax completely fused into pterothorax. The pterothorax broader than prothorax and slightly pointed medially on the abdomen. Pterothorax bears one long seta on either side at the posterolateral angles on its dorsal surface. The pro- and pterosterna are devoid of setae. Pterothoracic lateral margin is smooth. Pterothorax and first abdominal segment is separate. Abdominal segmentation is absent in first instar nymph. Spiracles on the abdomen are not distinct.

Second instar nymph: In general characters and 


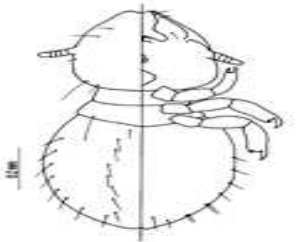

(1)

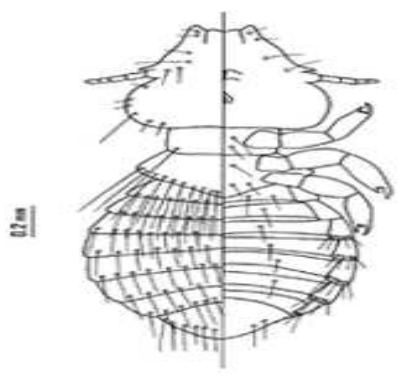

(3)

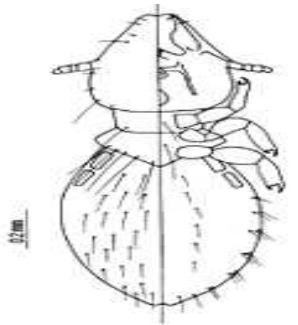

(2)

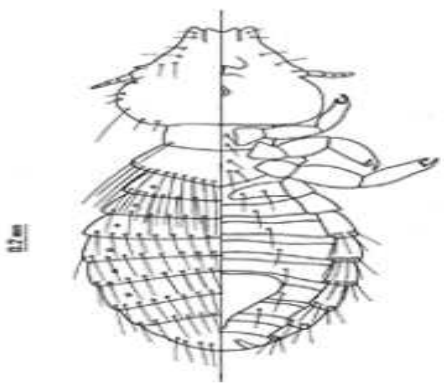

(4)

Fig.1-4. 1. First instar Nymph ; 2. Second instar Nymph; 3. Third instar Nymph (male) ; 4. Third instar Nymph (female) of Sturnidoecus bannoo.

appearance the second instar nymphs (Fig. 2) resembles the first intar nymph, but the size, chaetotaxy and pigmentation differ.

The description of second instar nymph is based on the characters of 4 days old specimens reared in the laboratory. The nymph measures $0.9 \mathrm{~mm}$ in length and $0.5 \mathrm{~mm}$ in width. Head is triangular with narrow anterior tapering clypeus. The hyaline margin becomes slightly straight. Anterior plate not properly developed. Marginal carina width medium to thick. Occipital carina short, thin and feebly seen, Preantennal nodus become large and rounded but not bulbulous. Conus are slightly developed. Cutting edges of mandible feebly seen. Antennae increase in length. Temple margin become rounded. The gular plate in now visible, due to pigmentation. Lingual sclerite feebly developed.

Marginal temporal seta (M.T.S.) 3 appears, one IInd anterior seta, one IIIrd anterior seta present on each half. Prothorax quadrangular with $1+1$ marginal seta. Pterothorax, short, projects laterally, latero-posterior angle with $5+5$ seta. Posterior margin obtusely angulated on the abdomen with one sub-median seta on each side. Abdomen ovate, segmentation poorly seen. Size of abdominal segment II not clear. Tergopleurites fused medially.

Third instar nymph: The third instar nymph (Fig. 3 and 4) resembles the second instar nymph in general appearance but for the first time sexual dimorphism in the characters of last abdominal segment become evident at this stage. This character enables the separation of nymph into two types; those with the rounded posterior end and partially developed genitalia produce the male after final moult and those in which posterior end is bilovate and partially formed vulvul margin become female after the final moulting. Male nymph measures 1.3 $\mathrm{mm}$ in length and $0.7 \mathrm{~mm}$ in width (Fig.3). Female nymph measures $1.5 \mathrm{~mm}$ in length and $0.8 \mathrm{~mm}$ in width (Fig.4). Other characters in which these differ from the second instar nymph and approach the adult stage are increase in size, straight hyaline margin, developed anterior plate and clearly seen thick marginal carina. Occipital carina broader at posterior side and joined with mandibles and preantennal nodus. Conus are completely developed. Ventral carina thick and clearly delineated. Antennae five segmented (with long, pedicel, scape larger than flagellomere) and monomorphic. Gular plate now clearly seen, bare, pointed at tip. Lingual sclerite becomes more developed.

Head chaetotaxy is similar to second instar nymph but at this stage IInd anterior ventral seta is also present on each half.

Prothorax with 1+1 marginal and 1+1 submarginal seta, pterothorax projecting laterally, posterior margins angulate on abdomen, with $10+10$ seta and $4+4$ submarginal seta. Sternum with $1+1$ seta. Mesothoracic spiracle present on the latero-posterior margin of prothorax. 
Abdominal segmentation clearly seen.Abdominal spiracles appear clearly from III to VIII segment. Abdominal segment II not deeply embedded dorsally within abdominal segment III. Abdominal segment II margin partially enclosed by pterothorax. Dorsal medial division of abdominal segment II is absent. Size of abdominal segment II approximately the same size as abdominal segment III. Abdominal segment II to III completely separate. Tergoplurites broken medially and separated by a wide gap.

\section{DISCUSSION}

Three nymphal instars of phthirapteran species differ in length of body (dimension of body parts) (Clay, 1958; Lonc and Modrejewska 1986 and 1989; Page et al., 1995; Saxena et al., 1998; Smith, 2000; Cicchino and Castro 2002; Silke, 2006 and Modrejewska and Zlotorzycka, 1987). Nymphs of certain specialized groups can be characterized by the modifications of setae (gradual modification in adults). For instance, in successive instars, the number of setae transformed into thorns on osculum. In certain species (eg. Columbicola columbae) clypeal setae develop in third instar. Gradual appearance of new setae and darkening of sclerites in nymphs have been noted by the aforesaid workers. Diagnosis of the nymphal instars through progression of chaetotaxy has been recommended by Clay (1958). Smith (2000) noted the ontogenic transformation in shape of head of three nymphal instars of four avian lice and recommended the use of nymphal morphology to establish phylogeny and taxonomy of avian lice.

In case of S. bannoo the Ist instar can be differentiated from IInd instar due to absence of tergal setae on prothorax, absence of anterior sternal setae, decreasement in number of tergal setae on pterothorax, abdominal segment III to VII, pleural setae on segment IV to VIII, absence of sternal setae on segment II to VII and segmentation.

IInd instars can be differentiated from third instar due to absence of sternal setae on prothorax, decresement of tergal setae and the absence of marginal sternal setae on pterothorax and decresement in number of tergal setae on abdominal segment II to VIII, pleural setae on IV to VII.

\section{ACKNOWLEDGEMENTS}

The authors are thankful to the Principal, Govt. Raza P. G. College, Rampur for laboratory facilities, to Chief Wild Life Warden of U. P. for permission for catching the birds and to the CSIR, New Delhi, India for providing financial support to Dr. A. K. Saxena, in the form of project no 37/ (1298)/07/EMR II.

\section{REFERENCES}

Cicchino A.C. and Castro, D.C. (2002). Nymphal stages of Abrocomophaga hellenthali (Phthiraptera: Gyropidae), a parasite of Octodon degus (Rodentia, Octodontidae). Iheringia, Serie Zoologia Porto Alegre, 92(4): 19-24.

Clay, T. (1958). Revisions of Mallophaga genera Degeeriella from the Falconiformes. Bulletin of British Museum Natural History on Entomology (London), 7: 123-207.

Gupta, N., Kumar, S. and Saxena, A. K. (2007). Intrinsic rate of natural increase of Brueelia amandavae (Ischnocera, Phthiraptera) infesting Indian red avadavat. Biologia, 62/ 4: 458-461.

Lonc, E. and Modrezejewska, M. (1986). An attempt to identification of nymphal instars of bitting lice (Mallophaga) using discriminent fuction. Bulletin entomologiquede pologme, Tom 56:631-640.

Lonc, E. and Modrezejewska, M. (1989). Growth rules applied to the stage identification of nymphal instars of some mallophogan species (Phthiraptera). Deutsch Entomology, 36:121-126.

Mey, E. (1994). Beziehungen Zwischen larvemorphologie und systematik der adulti bei den vogel-Ischnozeren (Insecta, Phthiraptera, Ischnocera). Mitteilungen aus dem Zoologischen Museum, Berlin, 70: 3-84.

Modrzejewska, M. and Zlotorzycka, J. (1987). Studies on morphology of nymphs of selected Amblycera and Ischnocera (Mallophaga). Polskie Pism Entomologiczne, 57:657-672.

Page, R. D. M., Price, R.D. and Hallenthal, R.A. (1995). Phylogeny of Geomydoecus and Thomodoecus pocket gopher lice (Phthiraptera : Trichodectidae) inferred from cladistic analysis of adult first instar morphology. Systems Entomology, 20: 129-143.

Price, R. D. and Hellenthal, R. A. (1996). Taxonomic importance of first instar chewing lice (Phthiraptera: Philoterpidae) from neotropical antbirds and Giant eaters (Aves: Passeriformes). Journal of Kansas Entomological Society, 69: 346-356.

Saxena, A. K., Surman, S. K. Singh and A. Kumar (1998). Description of life history stages of poultry shaft louse, Menopon gallinae (Phthiraptera: Amblycera, Menoponidae). Rudolstadter Naturhistorischce Schriften, 9: 81-85.

Silke, K., Michael, O. and Ragnar, K. (2006). Identification of larval instars of the Phthiraptera Ectoparasite Campanulotes bidentatus compar. (Burmeister, 1838) by the setal patterns. Deutsch, Entomology Z. 53: 86-90.

Smith, V.S. (2000).Basal ischnoceran louse phylogeny (Phthiraptera : Ischnocera : Goniodidae and Heptapsogasteridae). Systematic Entomology, 25: 73-94. 